\title{
PENGARUH DISIPLIN KERJA TERHADAP KINERJA PEGAWAI PADA KANTOR KECAMATAN CENGKARENG JAKARTA BARAT
}

\author{
Syukron Sazly ${ }^{1}$, Winna ${ }^{2}$ \\ ${ }^{1}$ Universitas Bina Sarana Informatika \\ Jln Kamal Raya No.18 Ring Road Barat, Cengkareng, Jakarta Barat \\ e-mail: syukron.szy@bsi.ac.id \\ ${ }^{2}$ Universitas Bina Sarana Informatika \\ Jln Kamal Raya No.18 Ring Road Barat, Cengkareng, Jakarta Barat \\ e-mail: oei.winnna@gmail.com
}

\begin{abstract}
Work Discipline is directly related to employee performance. Work discipline perceived directly by employees can reduce performance or improve employee performance. Employees who feel disciplined about the work they get will have an impact on the overall performance of a goverment agency.This research was undertaken to know the influence of discipline of work on employee performance who work at the office of Kecamatan Cengkareng - Jakarta Barat. The method of data collection are observations, litteratures study, documentations and questionnaires. The Method used is a descriptive quantitative analysis method that aims to know whether there is influence of work discipline on employee performance or not. It was held at April 30, 2018 untill May 30, 2018. Test of research instrument using SPPS 22 program that got from 30 respondents. The correlation test is strongly correlated caused exists at interval of 0,600-0,799, that means $r$ table $>r$ count at 0,644>0,361. It meeans that there is an influence of work discipline to the performance of as $41.4 \%$ and the rest, $58.6 \%$ influenced by other factors. So, based on the results of the regression test can be concluded that the discipline of work have a significant and strong effect on employee performance working at the office of Kecamatan Cengkareng, Jakarta Barat.
\end{abstract}

Key word: Work Discipline, Work Performance, Employee Performance

\section{PENDAHULUAN}

Instansi pemerintah adalah organisasi yang merupakan kumpulan orang-orang yang dipilih secara khusus untuk melaksanakan tugas negara sebagai bentuk pelayanan kepada orang banyak.Tujuan instansi pemerintah dapat dicapai apabila mampu mengolah, menggerakkan dan menggunakan sumber daya manusia yang dimiliki secara efektif dan efisien.Peran manusia dalam organisasi sebagai pegawai memegang peranan yang menentukan karena salah satu keberhasilan suatu instansi pemerintah tergantung pada manusia.

Disiplin kerja merupakan suatu instrumen yang digunakan para pemimpin untuk berkomunikasi kepada para pegawainya. Disiplin juga merupakan suatu kepatuhan dari orang-orang dalam instansi terhadap peraturan-peraturan yang ditetapkann sehingga menimbulkan keadaan tertib. Peningkatan kinerja pegawai juga sangatlah penting, karena diharapkan dapat memberikan pelayanan dengan sebaik-baiknya kepada masyarakat. Untuk melaksanakaan tugas pemerintahan dan pembangunan, seorang pegawai negeri sipil sebaiknya bekerja profesional, jujur, adil, dan tanggung jawab. Hal itu karena dapat meningkatkan kinerja menjadi efisien, efektif, melaksanakan serangkaian tugas yang dibebankan kepada pegawai.

Kantor Kecamatan Cengkareng adalah badan pemerintahan yang bergerak di bidang pelayanan publik yang meliputi kegiatan pengawasan, pengendalian dan penertiban terhadap segala sesuatu mengenai pelayanan publik dilingkungan kantor kecamatan Cengkareng. Sehubungan dengan hal tersebut, pegawai kantor kecamatan Cengkareng merupakan instansi pemerintah yang bertugas memberikan pelayanan kepada masyarakat secara efektif, efisien, transparan dan akuntabel dalam menyelenggarakan tugas negara, pemerintah dan pembangunan Kedudukan dan peranannya yang penting menyebabkan pegawaipegawainnya senantiasa dituntut supaya memiliki kesetiaan dan ketaatan penuh secara maksimal dalam menjalankan

tugas-tugasnya. Oleh sebab itu, setiap pegawai sebaiknya akuntabel dalam menjalankan tugas yang diberikan. Begitu pentingnya unsur disiplin dalam membangun kinerja pegawai maka penulis ingin mengetahui bagaimana tingkat disiplin pegawai kantor Kecamatan Cengkareng dan pengaruh nya terhadap kinerja pegawai pada kantor Kecamatan Cengkareng tersebut. 


\section{Disiplin Kerja}

Menurut (Rivai, 2011) disiplin kerja adalah suatu alat yang digunakan para pimpinan atau manajer untuk berkomunikasi dengan karyawannya agar mereka bersedia untuk mengubah suatu perilaku serta sebagai suatu upaya untuk meningkatkan kesadaran dan kesediaan seorang mentaati semua peraturan perusahaan atau organisasi dan norma-norma yang berlaku.

Malayu S.P Hasibuan dalam (Irawan, Roy, 2018) berpendapat kedisiplinan adalah kesadaraan dan kesediaan seseorang menaati semua peraturan perusahaan dan norma-norma sosial yang berlaku. Menurut Anoraga dalam (Liyas, Jeli Nata, 2017) disiplin adalah latihan batin dan watak dengan maksud upaya perbuatannya selalu mentaati tata tertib dan ketaatan pada aturan tata tertib.

Menurut Davis yang dikutip oleh Mangkunegara dalam (Suhardoyo, 2017) mengemukakan bahwa disiplin kerja dapat diartikan sebagai pelaksanaan manajemen untuk memperteguh pedoman-pedoman organisasi. Terry, dalam (Sutrisno, 2014) mengatakan bahwa disiplin merupakan alat penggerak karyawan. Agar tiap pekerjaan dapat berjalan dengan lancar, maka harus diusahakan agar tiap pekerjaan dapat berjalan dengan lancar, maka harus diusahakan disiplin yang baik

Menurut Peraturan Pemerintah Nomor 53 Tahun 2014 Tentang Disiplin Pegwai Negeri Sipil dalam Pasal 3 ayat (11) diterangkan dengan jelas bahwa Pegawai Negeri Sipil wajib masuk kerja dan mentaati ketentuan jam kerja.Berdasarkan pendapat para ahli, dapat disimpulkan adalah disiplin kerja adalah alat penggerak karyawan untuk mematuhi tata tertib agar pekerjaannya berjalan dengan lancar.

\section{Dimensi Disiplin Kerja}

Menurut Singodimedjo dalam (Sutrisno, 2014), dimensi yang mempengaruhi disiplin kerja pegawai adalah : (1) Besar kecilnya pemberian kompensasi, berkaitan dengan ada tidaknya keteladanan pemimpin dalam perusahaan, (2) Ada tidaknya aturan pasti yang dapat dijadikan pegangan., (3) Keberanian pimpinan dalam mengambil tindakan, (4) Diciptakan kebiasaankebiasaan yang mendukung tegaknya disiplin.

\section{Indikator Disiplin Kerja}

Menurut Hasibuan dalam (Suhardoyo, 2017) pada dasarnya banyak indikator yang mempengaruhi tingkat kedisiplinan karyawan dalam suatu organisasi, diantaranya : (1) Tujuan dan kemampuan, (2) Teladan Pemimpin, (3) Balas Jasa, (4) Keadilan, (5) Waskat, (6) Sanksi Hukum, (7) Ketegasan dan (8) Hubungan Manusia

\section{Hambatan Disiplin Kerja}

Menurut (Saydam, 2016) bahwa hambatan pendisiplinan karyawan akan terlihat dalam suasana kerja berikut yaitu: (1) Tingginya angka absensi karyawan, (2) Sering terlambatnya karyawan masuk kantor atau pulang lebih cepat dari jam yang sudah ditentukan, (3) Menurunnya semangat dan gairah kerja, (4) Berkembangnya rasa tidak puas, saling curiga dan saling melempar tanggungjawab, (5) Penyelesaian pekerjaan yang lambat, karena karyawan lebih sering ngobrol daripada bekerja, (6) Tidak terlaksananya supervisi dan waskat (pengawasan yang melekat dari atasan) yang baik, dan (7) Sering terjadinya konflik antar karyawan dan pimpinan perusahaan.

\section{Kinerja Pegawai}

Menurut (Irawan, Roy, 2018) kinerja (performance) adalah hasil kerja yang konkrit, dapat diamati, dan dapat diukur. Sehingga kinerja merupakan hasil kerja yang dicapai oleh pegawai dalam pelaksanaan tugas yang berdasarkan ukuran dan waktu yangt telah ditentukan. Menurut (Sedarmayanti, 2017) kinerja bukan merupakan karakteristik seseorang, seperti bakat atau kemampuan, tetapi merupakan perwujudan dari bakat atau kemampuan itu sendiri.

Dengan demikian disimpulkan bahwa kinerja merupakan sebuah proses untuk menetapkan apa yang harus dicapai dan pendekatanya untuk mengelola dan pengembangan manusia melalui suatu cara yang dapat meningkatkan kemungkinan bahwa sasaran akan dicapai dalam jangka waktu tertentu baik pendek maupun panjang.

\section{Penilaian Kinerja Pegawai}

Terkait dengan penilaian kinerja, dalam pasal $75 \mathrm{UU}$ ASN disebutkan bahwa penilaian kinerja PNS bertujuan untuk menjamin objektivitas pembinaan PNS yang didasarkan pada sistem prestasi dan sistem karier. (Dharma, 2014) menyatakan evaluasi atau penilaian kinerja adalah sistem formal yang digunakan untuk menilai atau mengevaluasi kinerja karyawan secara periodik yang ditentukan oleh organisasi. Penilaian pelaksanaan pekerjaan merupakan pedoman dalam hal pegawai yang diharapkan dapat menunjukkan kinerja pegawai secara rutin dan teratur sehingga bermanfaat bagi bagi pengembangan karier pegawai yang dinilai maupun bagi organisasi secara keseluruhan. Pendapat Wirawan, dalam buku (Abdullah, 2017) menyatakan bahwa evaluasi atau penilaian kinerja adalah sebuah proses penilaian oleh penilai (pejabat) yang melakukan penilaian (appraisal) mengumpulkan informasi mengenai kinerja ternilai (pegawai) yang dinilai (appraise) yang didokumentasikan secara formal untuk menilai kinerja ternilai dengan membandingkan standar kinerjanya secara untuk membantu mengambil keputusan manajemen SDM.

\section{Tujuan Penilaian Kinerja Pegawai}

Tujuan penilaian kinerja karyawan menurut (Mangkunegara, 2013) pada dasarnya meliputi (1) Meningkatkan etos kerja, (2) Meningkatkan motivasi 
kerja,(3)untuk mengetahui tingkat kinerja karyawan., (4) Untuk mendorong pertanggungjawaban dari karyawan, (5) Pemberian imbalan yang sesuai, (6) Untuk pembeda antar pegawai, (7) Pengembangan SDM, (8) Alat untuk membantu dan mendorong pegawai agar inisiatif, (9) Mengidentifikasi dan menghilangkan hambatan agar kinerja menjadi baik, (10) Untuk memperoleh umpan balik dari pegawai, (11) Pemutusan hubungan kerja, (12) Memperkuat hubungan antar pegawai, dan (13) Sebagai penyalur keluhan yang berkaitan dengan masalah pekerjaan.

\section{Dimensi dan Indikator Kinerja Pegawai}

Sehubungan dengan ukuran prestasi kerja maka kinerja pegawai, menurut (Mangkunegara, 2013) diukur dengan indikator- indikator sebagai berikut: (1) Kuantitas hasil kerja, yaitu meliputi produksi kegiatan yangdihasilkan., (2) Kualitas hasil kerja, yaitu meliputi kesesuaian produksi kegiatan dengan acuan ketentuan yang berlaku sebagai standar proses pelaksanaan kegiatan maupunorganisasi dan (3) Tanggung jawab, adalah kesadaran akan kewajiban karyawan untuk melaksanakan pekerjaan yang diberikan perusahaan.

\section{Faktor-Faktor Yang Mempengaruhi Kinerja}

Tinggi rendahnya kinerja seorang pegawai tentunya ditentukan oleh faktor-faktor yang mempengaruhinya baik secara langsung ataupun tidak langsung. Menurut Keith Davis dalam (Mangkunegara, 2013) menyatakan bahwa faktor yang mempengaruhi kinerja antara lain: (1)Faktor kemampuan. Secara psikologis kemampuan (ability) pegawai terdiri dari kemampuan potensi (IQ) dan kemampuan realita (pendidikan). Oleh karena itu pegawai perlu ditempatkan pada pekerjaan yang sesuai dengan keahliannya, (2) Faktor motivasi, dimana motivasi terbentuk dari sikap (attitude) seorang pegawai dalam menghadapi situasi kerja. Motivasi merupakan kondisi yang menggerakkan diri pegawai terarah untuk mencapai tujuan kerja. Sikap mental merupakan kondisi mental yang mendorong seseorang untuk berusaha mencapai potensi kerja secara maksimal. Menurut (Mangkunegara, 2013) terdapat hubungan yang positif antara motif berprestasi dengan pencapaian kerja. Motif berprestasi adalah suatu dorongan dalam diri seseorang untuk melakukan suatu kegiatan atau tugas dengan sebaik baiknya agar mampu mencapai prestasi kerja (kinerja) dengan predikat terpuji.

Menurut (Mangkunegara, 2013) faktor-faktor kinerja terdiri dari faktor internal dan eksternal: Faktor internal yaitu faktor yang dihubungkan dengan sifat-sifat seseorang. Sedangkan, faktor eksternal adalah adalah faktor-faktor yang mempengaruhi kinerja seseorang yang berasal dari lingkungan, seperti perilaku, sikap dan tindakan - tindakan rekan kerja, bawahan atau pimpinan, fasilitas kerja, dan iklim organisasi. Dari uraian diatas dapat disimpulkan bahwa faktor yang mempengaruhi kinerja dapat bersumber dari dalam individu-individu maupun luar individu, tinggal bagaimana kebijakan organisasi mampu menyelaraskan antara faktor-faktor tersebut

\section{Model Penelitian}

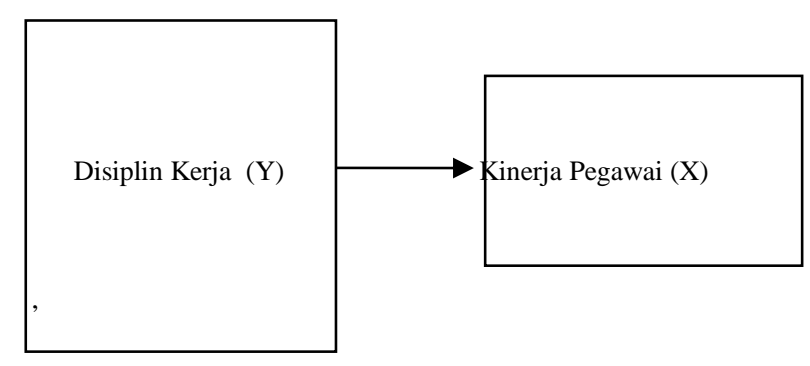

Sumber : Data Penelitian

Gambar 1. Model Penelitian

\section{$\underline{\text { Hipotesis }}$}

H0 : Tidak terdapat hubungan yang positif dan signifikan antara disiplin kerja dengan kinerja pegawai pada Kantor Kecamatan Cengkareng.

H1 : Terdapat hubungan yang positif dan signifikan antara disiplin kerja dengan kinerja pegawai pada Kantor Kecamatan Cengkareng.

\section{METODOLOGI PENELITIAN}

Yang menjadi obyek penelitian adalah tingkat disiplin kerja pegawai kantor Kecamatan Cengkareng, Kodya Jakarta Barat dan pengaruhnya terhadap kinerja mereka, Penelitian ini dilakukan pada tanggal 30 April 2018 sampai tanggal 30 Mei 2018. Penelitian ini termasuk jenis penelitian deskriptif kuantitatif, yaitu penelitian yang menggambarkan hubungan-hubungan dan pengaruh antar variabel yang diteliti.serta menguji hipotesa yang telah dirumuskan sebelumnya.

Pegawai di Kantor Kecamatan Cengkareng Jakarta adalah sebanyak 30 pegawai. Dalam penelitian ini penulis menjadikan seluruh pegawai kantor kecamatan Cengkareng sebagai sampel, sehingga disebut juga sample jenuh, karena seluruh populasi diperhitungkan sebagai sampel. Data primer dalam penelitian ini diperoleh dan dikumpulkan langsung dari tempat penelitian melalui kuisioner yang diberikan kepada para pegawai yang ditetapkan sebagai responden, sementar data sekunder dalam penelitian ini diperoleh dari dokumentasi kantor Kecamatan Cengkareng, terutama data yang berkaitan dengan struktur organisas, kebijakan-kebijakan dalam pelayanan dan lain lain.

Teknik Pengumpulan Data dalam penelitian ini adalah Studi Pustaka, yaitu pengumpulan data dengan menggunakan berbagai literatur kepustakaan.

Kuisioner, yaitu pengumpulan data dengan dengan daftar pernyataan yang digunakan untuk mengetahui persepsi responden terhadap beberapa variabel, Wawancara, yaitu teknik pengumpulan data dengan dengan melakukan tanya jawab secara langsung dengan 
narasumber agar mendapatkan informasi yang tidak terakomodasi dalam kuisioner serta Studi Dokumentasi, yaitu pengumpulan data dengan mengambil data langsung dari dokumen yang ada di Kantor Kecamatan Cengkareng yang diperlukan dalam penelitian ini.

\section{Definisi Operasional Variabel}

Tabel 1. Definisi Operasional Disiplin Kerja

\begin{tabular}{crr}
\hline VARIABEL & DIMENSI & INDIKATOR \\
\hline & & 1. Sesuai rencana dan jadwal \\
\hline Disiplin Kerja & Tujuan displin & 2. Menyelesaikan tujuan \\
$(\mathrm{X})$ & kerja & \\
\hline
\end{tabular}

\begin{tabular}{rr}
\hline & 3. Mengembangkan \\
\hline & kemampuan \\
\hline Faktor pendukung \\
\hline Disiplin kerja & 1. Teladan kepempimpinan \\
\hline & 2. Balas jasa \\
\hline Faktor penentu & 3.Keadilan \\
\hline displin kerja & 1.Pengawasan Melekat \\
\hline & 2. Sanksi Hukuman \\
\hline
\end{tabular}

Sumber : Mangkunegara (2013)

Tabel 2. Definisi Operasional Kinerja

\begin{tabular}{|c|c|c|}
\hline Variabel & DIMENSI & INDIKATOR \\
\hline & & 1. Kerapihan dalam \\
\hline \multirow[t]{20}{*}{ Kinerja Pegawai (Y) } & I. Kualitas Pekerjaan & $\overline{\text { melaksanakan tugas }}$ \\
\hline & & 2.Ketelitian dalam \\
\hline & & melaksanakan tugas \\
\hline & & 3. Hasil kerja yang \\
\hline & & diperoleh sesuai dengan \\
\hline & & target \\
\hline & Kuantitas Pekerjaan & 1. Kecepatan dalam \\
\hline & & $\overline{\text { menyelesaikan tugas }}$ \\
\hline & & 2. Kemampuan dalam \\
\hline & & menyelesaikan proses \\
\hline & & $\overline{\text { pekerjaan }}$ \\
\hline & & 3. Mampu menyelesaikan \\
\hline & & masalah pekerjaan \\
\hline & \multirow[t]{7}{*}{ 3. Tanggung jawab } & \\
\hline & & $\begin{array}{r}\text { Hasil kerja yang } \\
\text { sesuai }\end{array}$ \\
\hline & & target \\
\hline & & 2. Mengambil keputusan \\
\hline & & secara musyawarah \\
\hline & & 3. Mampu memperbaki \\
\hline & & kesalahan yang terjadi \\
\hline
\end{tabular}

Sumber : Mangkunegara (2013)

Uji Instrumen Penelitian
Uji validitas dalam penelitian ini akan digunakan untuk menguji masing- masing instrumen variabel yang digunakan dalam penelitian ini, dimana keseluruhan variabel penelitian memuat 18 butir pernyatan yang telah dijawab oleh 30 responden. Untuk menguji validitas dalam penelitian ini, penulis menggunakan bantuan program aplikasi SPSS 22 dan kemudian membandingkan $r$ hitung dengan menggunakan korelasi Bivarate Pearson (Product Moment Pearson) > $\mathrm{r}$ tabel. Jika nilai $\mathrm{r}$ hitung lebih dari $r$ tabel maka butir pernyataan dinyatakan valid.

Sementara itu, Uji Reliabilitas dilakukan untuk mengetahui apakah alat ukur yang telah disusun dapat digunakan untuk mengukur konsistensi alat ukur sehingga alat ukur tersebut dapat memberikan hasil yang sama bila digunakan berkali kali atau oleh orang yang berbeda. Ketentuannya, jika :

1. Nilai Cronbach Alpha 0,00 s.d 0,20, kurang reliabel

2. Nilai Cronbach Alpha 0,21 s.d 0,40 agak reliabel

3. Nilai Cronbach Alpha 0,41 s.d 0,60 cukup reliabel

4. Nilai Cronbach Alpha 0,61 s.d 0,80 reliabel

5. Nilai Cronbach Alpha 0,61 s.d 0,80 reliabel

6. Nilai Cronbach Alpha 0,81 s.d 1,00 sangat reliabel

Uji koefisien korelasi digunakan untuk mencari hubungan dan membuktikan hipotesis hubungan dua variabel berbentuk interval dan dari sumber data yang sama. Berikut rumus yang digunakan untuk mencari koefisien korelasi (r):

$$
r=\frac{n \mathbf{\Sigma} \mathbf{x y}-(\mathbf{\Sigma} \mathbf{x})(\boldsymbol{\Sigma} \mathbf{y})}{\sqrt{\sqrt{\left[n \boldsymbol{\Sigma} \mathbf{x}^{2}-(\boldsymbol{\Sigma} \mathbf{x})^{2}\left[\left[n \boldsymbol{\Sigma} \mathbf{y}^{2}-(\boldsymbol{\Sigma} \mathbf{y})^{2}\right]\right.\right.}}}
$$

Keterangan :

$\mathrm{r}$ : koefisien korelasi

$\mathrm{x}$ : disiplin kerja

y : kinerja pegawai

$\Sigma$ :jumlah

Tabel 3. Kategori Koefisien Korelasi

\begin{tabular}{lc}
\hline $\begin{array}{r}\text { Internal } \\
\text { koefisien }\end{array}$ & $\begin{array}{r}\text { Tingkat } \\
\text { Hubungan }\end{array}$ \\
\hline $0,00-0,199$ & $\begin{array}{c}\text { Sangat } \\
\text { rendah }\end{array}$ \\
\hline $0,200-0,399$ & Rendah \\
\hline $0,400-0,599$ & Sedang \\
\hline $0,600-0,799$ & Kuat \\
\hline $0,800-1,00$ & Sangat Kuat \\
\hline Sumber: (Sugiyono, 2014) &
\end{tabular}


Uji Determinasi digunakan untuk mengetahui seberapa jauh pengaruh variabel $\mathrm{X}$ terhadap variabel $\mathrm{Y}$ yang dinyatakan dalam persentase. Adapun rumusnya sebagai berikut,

$\mathrm{KD}=\mathrm{r}^{2} \times 100 \%$.

Keterangan :

$\mathrm{KD}$ : nilai koefisien determinasi

$\mathrm{r}$ : nilai koefisien korelasi

Pada model linear berganda ini, akan dilihat besarnya kontribusi untuk variabel bebas secara bersama-sama terhadap variabel terikatnya dengan melihat besarnya koefisien determinasi totalnya $\left(\mathrm{R}^{2}\right)$ Jika $\left(\mathrm{R}^{2}\right)$ yang diperoleh mendekati 1 (satu) maka dapat dikatakan semakin kuat model tersebut menerangkan hubungan variabel bebas terhadap variabel terikat. Sebaliknya jika $\left(\mathrm{R}^{2}\right)$ makin mendekati 0 (nol) maka semakin lemah pengaruh variabel- variabel bebas terhadap variabel terikat.

\section{HASIL DAN PEMBAHASAN}

Uji validitas dalam penelitian ini akan digunakan untuk menguji masing- masing instrumen variabelyang digunakan dalam penelitian ini, dimana keseluruhan variabel penelitian memuat18 butir pernyatan yang telah dijawab oleh 30 responden. Untuk menguji validitas dalam penelitian ini, penulis menggunakan bantuan program aplikasi SPSS 22dan22dan kemudian membandingkan $r$ hitung dengan menggunakan korelasi Bivarate Pearson (Product Moment Pearson) > r22dan kemudian membandingkan $r$ hitung dengan menggunakan korelasi Bivarate Pearson (Product Moment Pearson) > rr tabel. Jika nilai $r$ hitung lebih dari $r$ tabel makabutir pernyataan dinyatakan valid. Dalam hal ini jumlah sampel dalam penelitian yaitu $\mathrm{N}=30$ dan nilai signifikasi $5 \%$ atau 0,05 maka besarnya $\mathrm{r}$ tabel $=0,361$ (dengan melihat $\mathrm{r}$ tabel product moment pada lampiran). Berikut ini hasil uji validitas variabel disiplin kerja dan variabel kinerja pegawai.

Tabel 4. Hasil Uji Validitas Disiplin Kerja

\begin{tabular}{ccccc}
\hline $\begin{array}{c}\text { 'ernyata } \\
\text { an }\end{array}$ & r hitung & $5 \%$ & tabel & Keterangan \\
\hline 1 & 0,415 & 00.00 & 0,361 & Valid \\
\hline 2 & 0,525 & 00.00 & 0,361 & Valid \\
\hline 3 & 0,717 & 00.00 & 0,361 & Valid \\
\hline 4 & 0,626 & 00.00 & 0,361 & Valid \\
\hline 5 & 0,662 & 00.00 & 0,361 & Valid \\
\hline 6 & 0,67 & 00.00 & 0,361 & Valid \\
\hline 7 & 0,727 & 00.00 & 0,361 & Valid \\
\hline 8 & 0,5 & 00.00 & 0,361 & Valid \\
\hline 9 & 0,689 & 00.00 & 0,361 & Valid \\
\hline
\end{tabular}

Sumber: Hasil Penelitian (2018)
Tabel 5. Hasil Uji Validitas Kinerja Pegawai

\begin{tabular}{crccc}
\hline Pernyataan & r hitung & $5 \%$ & r tabel & Ket. \\
\hline 1 & 0,630 & 00.00 & 0,361 & Valid \\
\hline 2 & 0,842 & 00.00 & 0,361 & Valid \\
\hline 3 & 0,787 & 00.00 & 0,361 & Valid \\
\hline 4 & 0,712 & 00.00 & 0,361 & Valid \\
\hline 5 & 0,822 & 00.00 & 0,361 & Valid \\
\hline 6 & 0,671 & 00.00 & 0,361 & Valid \\
\hline 7 & 0,645 & 00.00 & 0,361 & Valid \\
\hline 8 & 0,645 & 00.00 & 0,361 & Valid \\
\hline 9 & 0,602 & 00.00 & 0,361 & Valid \\
\hline
\end{tabular}

Sumber : Data Hasil Penelitian (2018)

Berdasarkan tabel 4 dan 5 diatas, dilihat hasil uji dari 18 butir pernyataan yang diisi 30 responden menunjukkan bahwa semua nilai $r$ hitung lebih besar dari $r$ tabel, jadi semua butir pernyataan dapat dinyatakan valid.

Sementara itu, uji reliabilitas instrumen yang penulis gunakan yaitu teknik Cronbach Alpha dengan membandingkan nilai alpha dengan standarnya. Dalam hal ini nilai $r$ alpha harus lebih besar dari 0,600 agar dapat dianggap reliabel. Berdasarkan pengolahan data dengan bantuan SPSS 22 dan kuesioner yang telah dibagikan kepada 30 responden maka hasil uji reliabilitas penelitian ini disajikan pada tabel 6 dan 7 berikut ini :

Tabel 6. Hasil Uji Reliabilitas Disiplin Kerja

;ronbach's Alpha $\quad \mathrm{N}$ of Items

99

Sumber : Hasil olah data SPSS (2018)

Tabel 7. Hasil Uji Reliabilitas Kinerja Pegawai

;ronbach's Alpha J of Items

, $871 \quad 9$

Sumber : Hasil olah data SPSS (2018)

Tabel tersebut menunjukkan bahwa semua variabel mempunyai nilai Cronbach's Alpha variabel disiplin kerja adalah 0,792 dan Nilai Cronbach's Alpha pada variabel kinerja pegawai adalah 0,871 sehingga dapat 
dikatakan bahwa kriteria reliabilitas instrumen penelitian ini sangat tinggiBerdasarkan hasil penelitian skor pada pernyataan variabel ini sebesar 134 yang berada pada range skor sangat setuju dan rata-rata 4,47 yang berarti pegawai pada kantor Kecamatan Cengkareng mendekati sangat disiplin.Sementara itu untuk kinerja, rata-rata skor pada pernyataan variabel ini sebesar 129 yang berada pada range skor setuju dan rata-rata 4,3 yang berarti bahwa kinerja pegawai pada kecamatan cengkareng adalah mendekati sangat baik.

Berdasarkan perhitungan koefisien korelasi melalui SPSS 22 dalam tabel 8. Berikut ini, maka nilai $\mathrm{r}=$ 0,644 menyatakan bahwa terdapat hubungan yang signifikan antara variabel $\mathrm{X}$ (disiplin) dengan variabel Y (kinerja).

Tabel 8. Hasil Uji Korelasi

\begin{tabular}{lrr}
\hline & isiplin & inerja \\
\hline isiplin & 1 &, $644^{* *}$ \\
'earsonCorrelationSig. & 30 &, 000 \\
2-tailed) N &, $644^{* *}$ & 30 \\
\hline $\begin{array}{l}\text { inerjaPearsonCorrelat } \\
\text { on }\end{array}$ &, 000 & 1 \\
ig. (2- & 30 & 30 \\
tiled) N &
\end{tabular}

Sumber : Hasil olah data SPSS (2018)

Berdasarkan Tabel 9. Uji Koefisien Determinasi berikut ini dapat diketahui bahwa diketahui $\mathrm{r}^{2}$ adalah sebesar 0,414. Dari nilai tersebut dapat dilihat bahwa Kinerja dipengaruhi Disiplin sebesar 41,4\% dan sisanya dipengaruhi oleh hal-hal lain yang tidak diteliti oleh penulis.

Tabel 9. Hasil Uji Determinasi

\begin{tabular}{ccccc}
\hline & & \multicolumn{3}{c}{ Adjusted R Std. Error of } \\
Model & $\mathrm{R}$ & $\mathrm{R}$ Square & Square & the Estimate \\
\hline 1 &, $644^{\mathrm{a}}$ &, 414 &, 393 & 3,141
\end{tabular}

Sumber : Hasil olah data SPSS (2018)

Tabel 10. Hasil Uji Persamaan Regresi

\begin{tabular}{|c|c|c|c|c|c|}
\hline \multicolumn{6}{|c|}{ itandardized } \\
\hline \multirow[t]{2}{*}{ lodel } & \multicolumn{3}{|c|}{$\begin{array}{l}\text { Instandardized ;oefficients } \\
\text {;oefficients }\end{array}$} & \multirow[t]{2}{*}{$\mathrm{T}$} & \multirow[t]{2}{*}{ iig. } \\
\hline & $\mathrm{B}$ & itd. Error & Beta & & \\
\hline & 2,879 & 8,087 & & 356 & 725 \\
\hline & ,889 & ,200 & & ,449 & 300 \\
\hline $\begin{array}{l}\text { Jonstant) } \\
\text { lisiplin }\end{array}$ & \multicolumn{5}{|c|}{, 644} \\
\hline
\end{tabular}

Sumber : Hasil olah data SPSS (2018)
Nilai-nilai pada Tabel.10 kemudian dimasukkan kedalam persamaan regresi sebagai berikut.Pada tabel coefficients, kolom B pada constant (a) sebesar 2,879 sedangkan pada nilai Disiplin (b) sebesar 0,889. Sehingga persamaan regresinya dapat ditulis :

$$
\begin{aligned}
& Y=a+b X \\
& Y=2,879+0,889 X
\end{aligned}
$$

Dari persamaan tersebut dapat dijelaskan bahwa setiap penambahan 1 satuan nilai disiplin, maka nilai kinerja bertambah sebesar 0,889 pada konstanta 2,879.

\section{KESIMPULAN}

Berdasarkan penelitian yang diteliti penulis lakukan menggunakan metode penelitian kuantitatif menggunakan sumber data primer maka dapat ditarik kesimpulan sebagai berikut:

Dengan menggunakan uji korelasi maka dapat disimpulkan bahwa ada hubungan positif dan kuat antara disiplin kerja dengan kinerja pegawai karena $r$ hitung lebih besar dari pada $r$ tabel 0,644 >0,361. Serta tingkat hubungan antara disiplin kerja dan kinerja pegawai kuat dan berada pada interval 0,600-0,799. Dari hasil uji koefisien determinasi diperoleh pengaruh disiplin kerja terhadap kinerja pegawai sebesar $41,4 \%$ dan sisanya dipengaruhi faktor lain yang tidak dimasukkan kedalam penelitian ini.

Hasil uji regresi yang dilakukan dalam penelitian ini menghasilkan kesimpulan bahwa disiplin kerja (X) berpengaruh terhadap kinerja pegawai (Y), jadi $\mathrm{H} 0$ ditolak dan $\mathrm{H} 1$ diterima, karena nilai signifikan disiplin kerja $<0,05$ yaitu 0,000 . Persamaan regresi yang dihasilkan dari penelitian ini yaitu $\mathrm{Y}=2,879+0,889 \mathrm{X}$ yang berarti bahwa setiap peningkatan disiplin kerja sebesar 1, maka kinerja pegawai juga akan meningkat sebesar 0,889 pada konstanta 2,879.

\section{DAFTAR PUSTAKA}

Abdullah, M. (2017). Manajemen dan Evaluasi Kinerja Karyawan. Yogyakarta: Aswaja Pressindo.

Dharma, S. (2014). Manajemen Kinerja. Yogyakarta: Pustaka Pelajar.

Irawan, Roy, H. (2018). Pengaruh Disiplin Terhadap Kinerja Karyawan Pada PT Relasi Abadi Jakarta. Widya Cipta, 2(1), 1-10.

Liyas, Jeli Nata, R. P. (2017). Pengaruh Disiplin Kerj Terhadap Kinerja Karyawan Pada Bank Perkreditan Rakyat. Al-Masraf, 2(1), 1-10.

Mangkunegara, A. P. (2013). Evaluasi Kinerja SDM. Bandung: PT.Revika Aditama.

Rivai, V. dan E. S. (2011). Manajemen Sumber Daya 
Manusia Untuk Perusahaan. Jakarta: Rajawali Pers.

Saydam, G. (2016). Manajemen Sumber Daya Manusia (2nd ed.). Jakarta: PT.Bumi Aksara.

Sedarmayanti. (2017). Manajemen Sumber Daya Manusia Reformasi Birokrasi dan Manajemen Pegawai Negeri Sipil. Bandung. Bandung: PT Refika Aditama.

Sugiyono. (2014). Metode Penelitian Pendidikan Pendekatan Kuantitatif, Kuantitatif dan R\&D. Bandung: Alfabeta.

Suhardoyo. (2017). Hubungan Antara Prestasi Dan Disiplin Kerja Dengan Peningkatan Karier Pegawai Pada PT. Asconusa Air Transport. Perspektif, 15(1), 49-55.

Sutrisno, E. (2014). Manajemen Sumber Daya Manusia (6th ed.). Jakarta: Pranada Media Group.

\section{PROFIL PENULIS}

Syukron Sazly,SE,MM adalah seorang dosen Akademi Sekretari dan Manajemen Bina Sarana Informatika, yang yang belakang profesional yang dengan karir di beberapa perusahaan diberbagai bidang bisnis. Menyelesaikan pendidikan sebagai Sarjana Ekonomi, dari Fakultas Ekonomi Universitas Udayana, serta Magister Manajemen dari Universitas Mercu Buana . Penulis mengawali karir sebagai Management Trainee di Departemen Operasional Bank Danamon Indonesia, Tbk. Setelah tiga tahun sebagai professional untuk beberapa wilayah, yang juga di perbantukan pada Danamon Regional Training Centre sebagai Specific Trainer for Banking Fontliner penulis menutup karir sebagai Kepala Pelaporan untuk Bank Indonesia (BI) dan dilanjutkan selama delapan tahun kemudian sebagai professional di Allianz Life Indonesia, Daimler Chrysler Autorized Main Dealer, Start Up Portal Consultant dan HR Training and Consultant.

Winna adalah seorang alumni Universitas Bina Sarana Informatika, yang semasa kuliah aktif dalam berbagai kegiatan kemahasiswaan khususnya dalam Himpunan Mahasiswa Mahajemen Administrasi (HIMMA) Universitas Bina Sarana Informatika sebagai Bendahara Umum. Menyelesaikan pendidikan dasar di SD Baptis Cengkareng Indah (2002-2008), SMP Katholik Bintang Kejora (2008-2011), SMA Katholik Bintang Kejora(2011-2014) penulis sebelum melajutkan pendidikan di jurusan Manajemen Administrasi Universitas Bina Sarana Informatika memiliki karir sebagai Kepala Gudang Optik Bintang Jaya-Denpasar dengan track record yang memuaskan. 